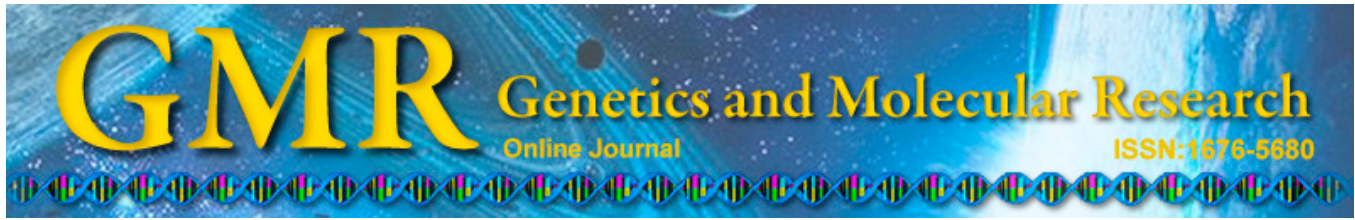

\title{
Polymorphisms of uric transporter proteins in the pathogenesis of gout in a Chinese Han population
}

\author{
W. Wan*, X. Xu*, D.B. Zhao, Y.F. Pang and Y.X. Wang \\ Department of Rheumatology and Immunology, \\ Shanghai Hospital of Second Military Medical University, Shanghai, China \\ *These authors contributed equally to this study. \\ Corresponding author: D.B. Zhao \\ E-mail: dongbaozhao@126.com
}

Genet. Mol. Res. 14 (1): 2546-2550 (2015)

Received March 6, 2014

Accepted July 25, 2014

Published March 30, 2015

DOI http://dx.doi.org/10.4238/2015.March.30.13

\begin{abstract}
In this study, we analyzed single nucleotide polymorphisms (SNP) in urate transporter genes to examine the pathogenesis of gout. We conducted a 1:1-matched case-control study that included 110 patients with acute gout attacks as the patient group and 110 healthy age- and gender-matched subjects as the control group. Clinical parameters were recorded and blood biochemistry tests were conducted for both groups. Multivariate logistic regression analysis was used to analyze the data. Hyperuricemia, hypercholesterolemia, and hypertriglyceridemia were found to be the main risk factors for the onset of gout, with relative risks of $29.2(\mathrm{P}<0.001), 25.5(\mathrm{P}=0.003)$, and 11.2 $(\mathrm{P}<0.001)$. For all detected SNP, rs2231142, located in ABCG2, showed the largest frequency differences for the $\mathrm{G} / \mathrm{G}, \mathrm{G} / \mathrm{T}$, and $\mathrm{T} / \mathrm{T}$ genotypes between groups: the distribution of these genotypes in the case group was 22, 49, and 26 individuals, respectively, and was 54, 38, and 9 individuals, respectively, in the control group. There was a statistically significant difference between the 2 groups $(\mathrm{P}<0.001)$ and the odds
\end{abstract}


ratio was $7.091(95 \%$ confidence interval $=2.867-17.541)$. Other SNPs (rs1165196, rs1165205, rs1183201, rs17300741, rs2078267, rs2242206, rs3733591, and rs9358856) showed no significant difference between the groups $(\mathrm{P}>0.05)$. The risk factors of gout were hyperuricemia, hypercholesterolemia, hypertriglyceridemia, and the $\mathrm{T} / \mathrm{T}$ genotype of the rs 2231142 locus in the $A B C G 2$ gene; expression of the $\mathrm{G} / \mathrm{G}$ genotype may be a protective factor against gout development.

Key words: Gout; $O A T$ gene; Pathogenesis; Transporter proteins

\section{INTRODUCTION}

Gout is a purine metabolic disorder that causes elevated serum uric acid or urate deposition in the tissues because of reduced uric acid excretion, which mainly occurs in cases of gouty arthritis, gouty nephropathy, and gouty kidney stone. Repeated acute gouty arthritis involves arthritis attacks, severe pain, and degeneration of the first metatarsophalangeal joint (Rafey et al., 2003). Uric acid is the end product of purine metabolism in humans (Kanellis and Kang, 2005; Dehghan et al., 2007; Ford et al., 2007). Genetic disorders of uric acid leading to hyperuricemia were shown to be associated with several factors, including a high purine diet, alcohol consumption, high fructose intake, purine metabolism, and impaired renal excretion of uric acid (Yang et al., 2010; Charles et al., 2011). It is important to understand factors affecting uric acid levels and improve the treatment of hyperuricemia to control uric acid levels in the blood. The level of uric acid is higher in humans than in other species because of higher uric acid invertase activity (Cummings et al., 2010). Serum uric acid levels depend on purine metabolism. Purines are consumed in food, produced by damaged cells when DNA and RNA purines are released, and secreted through intestinal secretion and uric acid reabsorption. Decreased renal excretion of uric acid contributes to increased serum uric acid levels. Uric acid anion transporters are expressed in the renal proximal tubule, and genetic variation in the coding transporter gene may result in hyperuricemia. To increase the understanding of genetic factors affecting uric acid levels, we examined 110 gout patients and 110 healthy controls of Han Chinese nationality to determine the minimum allele frequency in 9 single nucleotide polymorphism (SNP) loci of urate transporter genes.

\section{MATERIAL AND METHODS}

\section{Subjects}

We selected 110 gout patients between October 2012 and April 2013 who experienced a gout attack and visited our hospital. The patient age range was 20-69 years, with an average age of $51.5 \pm 11$ years. There were 107 males and 3 females. The control group included 110 healthy subjects who were 20-70 years of age, with an average age of $50.5 \pm 12$ years. There were 102 males and 8 females in the control group. There were no significant differences between the case group and the control group regarding gender and age $(P>0.05)$. This study was conducted in accordance with the Declaration of Helsinki and with approval from the Ethics Committee of the Second Military Medical University. Written informed consent was obtained from all participants. 


\section{SNP site selection}

Previous meta-analyses identified SNP sites involved in determining the serum uric acid level (Kolz et al., 2009; Stark et al., 2009), and the selected sites are shown in Table 1 .

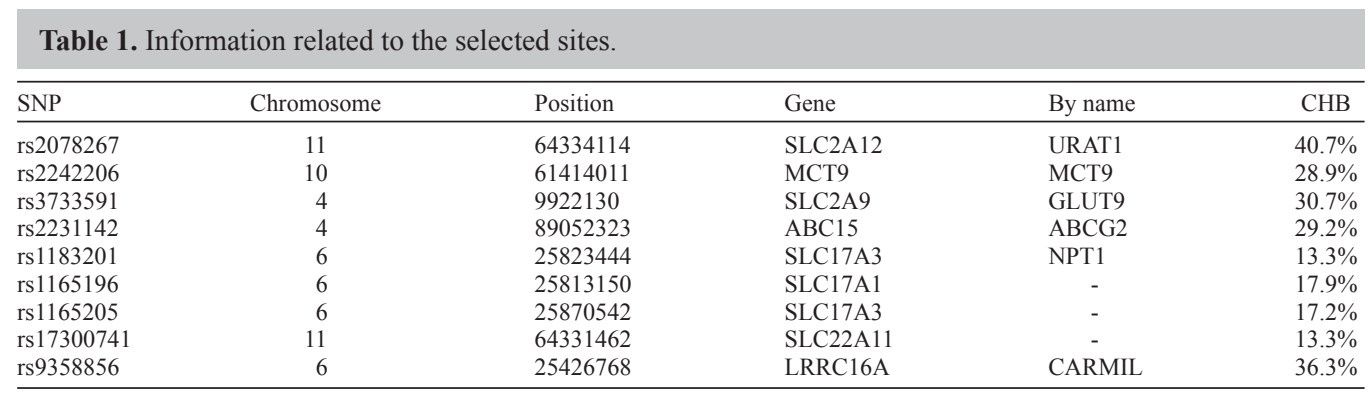

Peripheral blood samples were acquired from the 110 gout patients and 110 healthy controls. An extraction kit was used to extract genomic DNA from whole blood (Beijing Biodev-Tech Scientific \& Technical Co., Ltd., Beijing, China). The SNaPshot method was used according to the SNaPshot multifunctional kit instructions (Applied Biosystems, Foster City, CA, USA).

\section{Statistical analysis}

Data were analyzed using SPSS v. 20.0 (SPSS, Inc., Chicago, IL, USA), and the chi-square test was used for statistical comparison between groups to identify significant differences.

\section{RESULTS}

\section{Nine SNP loci}

We examined 2 groups of blood specimens for polymorphisms in 9 loci of uric acid transporter genes, and the corresponding sites were divided into different types (Table 2 ). Among the examined SNPs, the 3 genotypes in the rs 2231142 site of $A B C G 2, G / G$, $\mathrm{G} / \mathrm{T}$, and $\mathrm{T} / \mathrm{T}$, were found in 22,49 , and 26 patients, and in 54, 38, and 9 control subjects, respectively. The number of subjects with the G/T and T/T genotypes for the rs 2231142 locus in the patient group was higher than that in the control group, suggesting that these 2 genotypes may be pathogenic susceptibility genotypes. Statistical analysis showed a statistically significant difference between the 2 groups $(\mathrm{P}<0.001)$. The odds ratio value and $95 \%$ confidence interval for the rs 2231142 genotypes are shown in Table 3 . The other sites showed no statistically significant difference in genotype distribution between the two groups $(\mathrm{P}>0.05)$. 
Table 2. Case and control groups of genotypes in ten sites.

\begin{tabular}{|c|c|c|c|c|c|c|c|c|c|c|c|c|c|c|c|c|c|}
\hline \multirow[t]{2}{*}{ Site } & \multicolumn{8}{|c|}{ Genotype of case group } & \multicolumn{8}{|c|}{ Genotype of control group } & \multirow[t]{2}{*}{$P$ value } \\
\hline & $\mathrm{A} / \mathrm{A}$ & $\mathrm{C} / \mathrm{C}$ & $\mathrm{C} / \mathrm{T}$ & $\mathrm{G} / \mathrm{A}$ & $\mathrm{G} / \mathrm{G}$ & $\mathrm{G} / \mathrm{T}$ & $\mathrm{T} / \mathrm{A}$ & $\mathrm{T} / \mathrm{T}$ & $\mathrm{A} / \mathrm{A}$ & $\mathrm{C} / \mathrm{C}$ & $\mathrm{C} / \mathrm{T}$ & $\mathrm{G} / \mathrm{A}$ & $\mathrm{G} / \mathrm{G}$ & $\mathrm{G} / \mathrm{T}$ & T/A & $\mathrm{T} / \mathrm{T}$ & \\
\hline rs1165196 & 71 & 0 & 0 & 26 & 0 & 0 & 0 & 0 & 64 & 0 & 0 & 31 & 3 & 0 & 0 & 0 & 0.234 \\
\hline rs1165205 & 72 & 0 & 0 & 0 & 0 & 0 & 25 & 0 & 64 & 0 & 0 & 0 & 0 & 0 & 34 & 3 & 0.115 \\
\hline rs 1183201 & 0 & 0 & 0 & 0 & 0 & 0 & 25 & 72 & 3 & 0 & 0 & 0 & 0 & 0 & 33 & 65 & 0.147 \\
\hline rs 17300741 & 80 & 0 & 0 & 13 & 2 & 0 & 0 & 0 & 86 & 0 & 0 & 15 & 0 & 0 & 0 & 0 & 0.513 \\
\hline rs2078267 & 0 & 93 & 3 & 0 & 0 & 0 & 0 & 0 & 97 & 4 & 0 & 0 & 0 & 0 & 0 & 0 & 0.528 \\
\hline rs2231142 & 0 & 0 & 0 & 0 & 22 & 49 & 0 & 26 & 0 & 0 & 0 & 0 & 54 & 38 & 0 & 9 & 0.000 \\
\hline rs 2242206 & 0 & 0 & 0 & 0 & 12 & 53 & 0 & 31 & 0 & 0 & 0 & 0 & 18 & 44 & 0 & 37 & 0.142 \\
\hline rs3733591 & 0 & 12 & 49 & 0 & 0 & 0 & 0 & 36 & 0 & 9 & 46 & 0 & 0 & 0 & 0 & 45 & 0.239 \\
\hline rs9358856 & 8 & 0 & 0 & 37 & 52 & 0 & 0 & 0 & 9 & 0 & 0 & 44 & 48 & 0 & 0 & 0 & 0.243 \\
\hline
\end{tabular}

Table 3. OR value and $95 \% \mathrm{CI}$ between the two groups in the rs 2231142 site.

\begin{tabular}{lcccc}
\hline Group & \multicolumn{3}{c}{ rs2231142 genotype } & OR (95\%CI \\
\cline { 2 - 4 } & $\mathrm{G} / \mathrm{G}$ & $\mathrm{G} / \mathrm{T}$ & $\mathrm{T} / \mathrm{T}$ & \\
\hline Case group & 22 & 49 & 26 & $7.091(2.867-17.541)$ \\
Control group & 54 & 38 & 9 & \\
\hline
\end{tabular}

\section{DISCUSSION}

Gout involves an increase in uric acid, which is the end product of purine metabolism in the human body, and occurs because of the lack of uric acid enzyme, degradation of uric acid allantoin, and uric acid salt for eventual excretion by the kidneys. Serum uric acid levels reflect the formation and excretion of uric acid (Wu et al., 2008; Kolz et al., 2009; Stark et al., 2009). The complex process of renal excretion of uric acid has been extensively examined in a number of studies. The excretion of uric acid occurs in 4 steps, through glomerular, renal proximal tubular reabsorption and secretion, and renal tubular resorption. Studies suggest that during glomerular filtration of uric acid, nearly all absorption, secretion, and reabsorption of uric acid represent only about $10 \%$ of the discharge in vitro.

ATP-binding cassette, sub-family G, member 2 (ABCG2) is an ATP-binding cassette half-transporter whose gene is located on chromosome 4q22 and is expressed in the placenta, pharynx, bladder, brain, intestine, and kidney. Matsuo et al. (2009) found that in 161 gout patients, $80 \%$ showed $A B C G 2$ mutations that decreased uric acid secretion, increasing the risk of gout by 26-fold. ABCG2 is mainly expressed on the proximal side of luminal membranes, and must be the same type of 2-mer to function in the transport of uric acid.

In a study of subjects from Italy and the United Kingdom, serum uric acid levels were significantly influenced by glucose transporter 9 (GLUT9) sequence variation ( $\mathrm{Li}$ et al., 2007). GLUT9 in the kidney and liver functions to transport uric acid and fructose. In this study, we found expression of the A/A and G/A genotypes for the SNP rs3733591 of the GLUT9 gene in both cases and controls, with no statistical difference between the groups. A genome-wide association study showed that this may be related to the 2 loci of CHB lower.

Urate transporter 1 (URAT1) is the main transporter involved in uric acid reabsorption in the luminal membrane. Epithelial cells on the proximal convoluted tubule side specifically express URAT1, causing uric acid reabsorption from the renal tubular lumen and epithelial cells, which is critical for maintaining blood uric acid levels of the ion channel (Vitart et al., 2008). Shima et al. (2006) investigated the rs893006 polymorphism of the SLC22A12 gene, 
which encodes URAT1 in 326 Japanese subjects, and found a significant association between the GG genotype and hyperuricemia. Clinical reabsorption and excretion of uric acid by the URAT1 agents probenecid, sulfinpyrazone, benzene bromine malone, and NSAIDs interfere with uric acid excretion (Shima et al., 2006).

SLC16A9 encodes MCT9-related sites of rs12356193, and SLC17A3-encoded URAT1 loci containing rs1165205 have been shown to be associated with uric acid concentration (Enomoto et al., 2009). However, in our study, SNP site scanning results from these genes showed no statistically significant difference between groups. Enomoto et al. (2009) suggested that the $S L C 2 A 9$ coding gene loci rs 734553 and rs6855911, encoded by the $A B C G 2$ gene locus rs2231142, was closely associated with gout.

Expression analysis of the rs2231142 locus of the $A B C G 2$ gene in a Han Chinese population with gout showed that the T/T genotype may be an important risk factor of gout, while expression of the $\mathrm{G} / \mathrm{G}$ genotype may be a protective factor. No clear correlation was observed for the other 8 loci examined.

\section{ACKNOWLEDGMENTS}

Research supported by the Shanghai Municipal Science and Technology Commission and Young Doctor Funding of Chang Hai Hospital.

\section{REFERENCES}

Charles BA, Shriner D, Doumatey A, Chen G, et al. (2011). A genome-wide association study of serum uric acid in African Americans. BMC Med. Genomics 4: 17.

Cummings N, Dyer TD, Kotea N, Kowlessur S, et al. (2010). Genome-wide scan identifies a quantitative trait locus at 4p15.3 for serum urate. Eur. J. Hum. Genet. 18: 1243-1247.

Dehghan A, van Hoek M, Sijbrands EJ, Hofman A, et al. (2007). High serum uric acid as a novel risk factor for type 2 diabetes mellitus. Diabetes Care 31: 361-362.

Enomoto A, Kimura H, Chairoungdua A, Shigeta Y, et al. (2009). Molecular identification of a renal urate anion exchanger that regulates blood urate levels. Nature 417: 447-452.

Ford ES, Li C, Cook S and Choi HK (2007). Serum concentrations of uric acid and the metabolic syndrome among US children and adolescents. Circulation 115: 2526-2532.

Kanellis J and Kang DH (2005). Uric acid as a mediator of endothelial dysfunction, inflammation, and vascular disease. Semin. Nephrol. 25: 39-42.

Kolz M, Johnson T, Sanna S, Teumer A, et al. (2009) Meta-analysis of 28,141 individuals identifies common variants within five new loci that influence uric acid concentrations. PLoS Genet. 5: e1000504.

Li S, Sanna S, Maschio A, Busonero F, et al. (2007). The GLUT9 gene is associated with serum uric acid levels in Sardinia and Chianti Cohorts. PLoS Genet. 3: e194.

Matsuo H, Takada T, Ichida K, Nakamura T, et al. (2009). Common defect of ABCG2, a high capacity urate exporter cause gout: a function based genetic analysis in a Japanese population. Sci. Transl. Med. 1: 5ra11.

Rafey MA, Lipkowitz MS, Leal PE and Abramson RG (2003). Uric acid transport. Curr. Opin. Nephrol. Hypertens. 12: 511-516.

Shima Y, Teruya K and Ohta H (2006). Association between intronic SNP in urate-anion exchanger gene, SLC22A12, and serum uric acid levels in Japanese. Life Sci. 79: 2234-2237

Stark K, Reinhard W, Grassl M, Erdmann J, et al. (2009). Common polymorphisms influencing serum uric acid levels contribute to susceptibility to gout, but not to coronary artery disease. PLoS One 4: e7729.

Vitart V, Rudan I, Hayward C, Gray NK, et al. (2008). SLC2A9 is a newly identified urate transporter influencing serum urate concentration, urate excretion and gout. Nat. Genet. 40: 437-442.

Wu EQ, Patel PA, Yu AP, Mody RR, et al. (2008). Disease-related and all-cause health care costs of elderly patients with gout. J. Manag. Care Pharm. 14: 164-175.

Yang Q, Wu H, Guo CY and Fox CS (2010). Analyze multivariate phenotypes in genetic association studies by combining univariate association tests. Genet. Epidemiol. 34: 444-454. 